\title{
Dekonstruski Inferioritas Perempuan (Pendekatan Feminisme Agama)
}

\author{
Shulhan Al-finnas \\ Rusti Rahayu
}

\begin{abstract}
This article is aimed to discuss about women position which is usually put in second part at social class. Deconstructing woman inferiority will be studied by using religious feminism at this article. This is result of qualitative research based on library study by looking at previous articles discuss the theme then analyzing them through religious feminism approach. The finding approves that emergence of sub-class woman are affected by people understanding about Islamic religious constructed by interpreter thoughts and Islam figures views which lead social believe and assumption. In addition, physical woman that needs man protection welcomes the emergence of women inferiority. Basically, the woman is created softly and weak more than man. It forces her to be protected by male like husband and enables him to arrogantly treat her inhuman.
\end{abstract}

Keyword: Deconstruction, Inferiority, Approach, Feminism

\section{Pendahuluan}

Setiap manusia memimpikan kehidupan yang nyaman, harmonis dan penuh kehangatan. Hubungan yang dibangun antara umat manusia secara spesifik antara laki-laki dan perempuan yang ideal adalah yang mencerminkan dinamika sosial yang berkeadilan dengan menempatkan perempuan sebagai patner kerja dalam setiap aktivitas sosial masyarakat. Kaum laki-laki dan perempuan dalam skala makro (publik) dan mikro (privat) menjalankan kelangsungan hidup dengan azas take and give dengan tidak membentuk sistem atas bawah tetapi berjalan selaras (koordinatif) dengan menyeimbangkan hak dan kewajiban.

Dengan demikian, kehidupan akan berjalan dengan spirit masa depan yang gemilang di antara laki-laki dan perempuan dan terciptanya tatanan yang prima dan profesional. Keberlangsungan generasi umat manusia sangat dipengaruhi oleh kerja sama kedua belah pihak antara laki-laki dan perempuan.

Itulah sebabnya tidak ada alasan kaum laki-laki memperlakukan kaum perempuan sebagai makhluk kedua, kelas kedua dalam ruang aktualisasi kedua setelah kaum laki-laki. Keberlangsungan hidup sangat ditentukan oleh seorang Ibu yang pasti berjenis kelamin 
perempuan sehingga setiap individu di bumi ini berhutang jasa yang sangat besar kepada perempuan yang menjadi salah satu medium terpenting dalam menjembatani keberlangsungan hidup umat manusia.

Sayangnya, kondisi realitas di lingkungan masyarakat masih banyak dijumpai kasus yang memperlakukan perempuan tidak semestinya. Banyak kasus tentang kriminalisasi, marginalisasi dan eksploitasi terhadap kaum perempuan. Contoh kasus kriminalisasi terhadap perempuan adalah yang sering terjadi kekerasan seksual dan kekerasan dalam rumah tengga (KDRT). Sementara contoh kasus marginalisasi terhadap perempuan dapat berbentuk pembatasan akses pendidikan di tempat-tempat tertentu yang masih primitif dan konservatif. Sementara bentuk eksploitasi terhadap perempuan sering kali berupa penempatan kerja dari pos-pos strategis untuk meraih keuntungan besar dengan mengatasnamakan emansipasi.

Fakta sosial ini menarik sekali jika ditinjau dalam pendekatan feminisme agama. Pengkajian ini dimaksudkan untuk mengetahui aspek-aspek yang memicu terjadi perilaku ini. Setelah latar belakang munculnya kasus ini diketahui dengan akurat, kegiatan berikutnya adalah memformulasikan penyelesaian (problem solving) terhadap masalah krusial ini. Dalam kajian kesempatan ini, penulis akan mengkaji secara spesifik polemik dinamika kejahatan terhadap kaum perempuan.

\section{Metode Penelitian}

Metode yang digunakan dalam penulisan ini adalah metode analisis kualitatif. Tulisan ini merupakan hasil penelitian dengan pendekatan library research yaitu dengan cara mengkaji teksteks terkait dan dihubungkan dengan kondisi terkini untuk merumuskan pemikiran baru. untuk menguatkan analisis, contoh kasus diambil seperti kejahatan yang dilakukan oleh laki-laki berinisal HS selama tujuh tahun sejak tahun 2016 menyetubuhi anak tiriinya sejak usia 16 tahun. perlakuan tersebut dilakukan di rumah mereka di kawasan Jakarta Selatan. ${ }^{62}$ Kasus lain adalah seorang suami berinisial Ch (34 tahun) di Jawa Timur tega menjual istrinya ke orang lain untuk digauli secara bersama-sama. Perbuatan itu berlangsung sebanyak tiga kali. Ch memaksa istrinya melakukan hal tersebut hanya untuk mendapatkan uang dan untuk melancarkan aksinya Ch

\footnotetext{
${ }^{62}$ Diakses dari https://m.detik.com/news/berita/d-2368150/bejat-ayah-setubuhi-anak-tirinya-selama-7tahun-di-jakarta-selatan, pada tanggal 05 Juni 2018 pukul 19.00.
} 


\section{An-Nisa', Volume XI Nomor 1 Januari 2018}

mempromosikan istrinya lewat akun pribadinya difacebook. ${ }^{63}$ Selain itu kasus yang dialami oleh seorang wanita berinisial SA, dia dibunuh kemudian dimutilasi dan mayatnya dibuang di beberapa tempat yang berbeda oleh suaminya sendiri (MK 23) hal tersebut dipicu karena persoalan ekonomi. ${ }^{64}$

\section{Dekonstruksi Paradigma Inferioritas}

Dua kasus di atas ini hanyalah contoh fenomenal tentang kajahatan terhadap perempuan. Kejadian ini merupakan fakta sosial yang sangat menarik untuk dikaji secara mendalam dan intensif agar menemukan jawaban latar belakang terjadinya kasus tersebut dalam kacamata feminisme agama.

Adapun kedua kasus di atas pada dasarnya sangat berpeluang untuk dikaji menggunakan pendekatan multidimensional baik pendekatan historis, normatif, fenomenologi, sosiologis, antropologis, psikologis tetapi kajian ini tidak mungkin mendalam karena mengkombinasikan berbagai pendekatan dengan analisis yang sederhana.

Dalam hal ini faktor mendasar adalah eksistensi perempuan sebagai makhluk sosial yang mendapat pandangan berbeda-beda dari kaum laki-laki. Kerena perempuan sebagai obyek utama yang dianggap menjadi pemicu munculnya pemasalahan sosial seperti pelecehan seksual, anarkisme terhadap perempuan, dan beberapa bentuk kriminalitas terhadap perempuan, pendekatan feminisme agama adalah satu piranti kajian yang sangat cocok untuk dijadikan alat menganalisis kasus ini. Dengan pendekatan feminisme dimungkinkan diketahui faktor-faktor apa saja yang menimbulkan pelecehan seksual terhadap perempuan. Perlakuan yang dialami perempuan jika dilihat dari kacamata feminisme secara umum dipengaruhi beberapa faktor, antara lain:

1) Pemahaman keagamaan

Dalam perkembangan keislaman, mayoritas kaum laki-laki yang banyak menyumbangkan pemikiran dan karya dalam membangun peradaban. Para pengembang pengetahuan dan keagamaan Islam tidak mungkin dapat melepaskan diri tendesius pribadinya dalam mengkaji dan

63 Syaiful Islam, "Bejat! Suami Jual Istri Lalu Diajak Threesome”, diakses dari https://www/google.co.id/amps/news.okezone.com/amp/2017/02/01/519/1607141/bejat-suami-jual-istri-laludiajak-threesome, pada tanggal 06 Juni 2018 pukul 06.02.

${ }^{64}$ "Suami yang Mutilasi Istri di Karawang Dikenal Penyayang", diakses dari https://www.google.co.id//amp/s/m.kumparan.com//@kumparannews/suami-yang-mutilasi-istri-di-karawangdikenal-penyayang.amp, pada tanggal 06 Juni 2018 pukul 05.39. 
menafsirkan teks skriptual islam. Tafsir dan pemahaman keislaman yang dikembangkan tidak mungkin bebas nilai. Ia selalu berhubungan erat dengan pengalaman, dan gesekan emosi para interpretator.

Marzuki mengatakan bahwa munculnya fenomena kekerasan gender terhadap perempuan karena tafsir keagamaan yang memihak kepentingan kaum laki-laki. Dalam kacamata gender, perempuan senantiasa menjadi sasaran kaum laki baik fisik maupun psikis. Terjadinya kekerasan tersebut bukan substansi ajaran agama Islam, tetapi merupakan dinamika perkembangan diskursus yang dikembangkan oleh kaum laki-laki untuk mendapatkan keuntungan dengan menafsirkan teks agama sesuai kehendaknya. ${ }^{65}$

Berdasarkan pendapat di atas terlihat dengan jelas bahwa tafsir keagamaan dan wacana keilmuan lainnya itu berkembang tidak bebas nilai (value free). Kajian tafsir keagamaan yang berkembang akan sarat dengan kepentingan penafsir sehingga muatan tafsir terebut akan sarat nilai (value laden). Setiap pelaku tafsir tidak mungkin dapat melepaskan intervensi sisi emosi pribadi dalam mengkaji sebuah persoalan dalam kajian tafsir sehingga obyektivitas ilmu tidak akan benar-benar dijumpai. Obyektivitas ilmu yang ada selama ini merupakan aklamasi subyektif yang tersistem dan membentuk pola pemikiran.

Untuk itu, Amin Adullah merumuskan tata kerja sains termasuk corak penafsiran adalah intersubjective testability. Istilah ini digunakan Amin untuk membangun hubungan ilmu lintas disiplin dengan model dialogis-Integratif. Disini dijelaskan bahwa obyek dan subyek sama-sama memiliki peranan dalam kegiatan keilmuan. Hal ini menjadikan konsep tidak serta merta muncul secara natural tetapi sangat diwarnai oleh ilmuwan sebagai experimental agent. Sebuah konsep dalam konstruksinya sangat dipengaruhi oleh pola pikir ilmuwan sebagai aktor yang kreatif. ${ }^{66}$

Pendapat Amin ini memberikan gambaran yang jelas arah perkembangan konstruksi sebuah konsep dalam ilmu tertentu. Pemikiran yang memposisikan kaum laki-laki diatas perempuan jelas merupakan hasil formulasi interaksi subyek, interpretator dan obyek, teks agama. Teks agama sebagai obyek kajian pada awalnya bebas nilai (dalam tanda kutip) tetapi kemudian akan

${ }^{65}$ Marzuki, Kekerasan gender dalam wacana tafsir keagamaan di Indonesia dalam perspektif islam (Yogyakarta: FISE-UNY, tt), h. 2.

66 M. Amin Abdullah, Agama, Ilmu dan Budaya; Paradigma Integrasi-Interkoneksi Ilmu Pengetahuan (Yogyakarta, Makalah disampaikan dalam pidato AIPI 17 Agustus 2013), h. 13. 


\section{An-Nisa', Volume XI Nomor 1 Januari 2018}

menajadi sarat nilai ketika pemikiran penafsir masuk ke dalamnya. Para penafsir merumuskan konsep yang ideal untuk dapat dikembangkan dalam kehidupan sehari-hari. Idealitas konsep tersebut tentu dalam perspektif kaum laki-laki kerena waktu itu perempuan tidak memiliki akses untuk masuk di dalam proyek penafsiran.

Dengan demikian, sakralitas konstruksi keagamaan dalam koridor tertentu ada yang perlu dikaji ulang. Posisi laki-laki lebih kuat atau lebih baik dari kaum perempuan itu bukan substansi teologi ajaran Islam. Para mufassir menjadikan kaum laki-laki lebih tingi dari perempuan dengan bersandar kepada ayat. "Arrijaalu Qauwaamuna 'ala an-nisaa'. ${ }^{7}$ Berangkat dari kata qouwmuuna ahli tafsir yang didominasi oleh kaum laki-laki mengatakan laki-laki itu labih kuat dari perempuan dari sisi satu perspektif subyektif dan tidak diasosiasi dengan ayat lain atau hadits. Di dalam hadist dijelaskan tentang human equality di hadapan Allah, Sang Pencipta (Inna akromakum 'Inda Allah atqookum). Semua manusia disisi Allah sama dan yang menentukan mulia tidaknya sesorang hanyalah tingkat ketakwaan.

Ayat ini sebenarnya jika lebih seksama diperhatikan adalah membahas tentang tugas dan tanggung jawab laki-laki dalam kehidupan rumah tangga dan kehidupan sosial dalam membentuk karakter perempuan. Laki-laki bertanggungjawab untuk membentuk karakter perempuan karena kaum laki-laki mendapatkan kematangan dalam berpikir yang realistis. Dengan perkataan lain, kekuatan laki-laki lebih dari perempuan baik dari segi fisik dan psikis, mereka harus mampu mengayomi kaum perempuan bukan malah melecehkan dan melakukan tindakan yang tidak manusiawi terhadap mereka. ${ }^{68}$

Untuk memahami esensi ayat dan hadits di atas, tidak cukup dengan hanya menguasai teknik membaca teks-teks arab. Untuk memahami Al-Qur'an dengan baik diperlukan beberapa instrumen penting agar tidak melahirkan produk penafsiran yang parsial dan terlalu memihak kepentingan golongan tertentu. Selain harus mampu menjangkau aspek historits turunnya alquran sebagai kausalitas mikro (Asbaabu An-nuzuul), penafsir harus mampu memaknai kontekstualitas ayat dihubungkan dengan perkembangan zaman dan realitas sosial. Mufassir

\footnotetext{
${ }^{67}$ Lihat Al-Qur' an dan Terjemahannya (Semarang: CV. Asy-syafa, 1999), h. 122.

${ }^{68}$ Lihat Muhammad Nawawi, Maaraah Labiid Tafsiir An-Nawawi, Jilid 1 (Surabaya: Alhidayah,
} Tahun Terbit), h. 149. 
harus mampu memetakkan wilayah tafsir ubudiyah (vertical sector), dan wilayah tafsir muamalah (horizontal sector).

\section{2) Esensi Tubuh Perempuan}

Dalam feminisme eksistensialisme, penindasan terhadap perempuan diawali dengan adanya beban reproduksi yang harus ditanggung oleh tubuh perempuan. Laki-laki menuntut perempuan untuk menjadi dirinya sendiri dan kemudian menjadi yang lain karena ia adalah makhluk yang seharusnya di bawah perlindungan laki-laki.

Perempuan diciptakan dari tulang rusuk laki-laki merupakan konsep yang melegitimasi munculnya posisi perempuan sebagian bagian yang lain dari laki-laki. Kaum laki-laki beranggapan perempuan adalah bagian dari hidupnya yang dapat dimanfaatkan sedemikian rupa sesuai keinginannya.

Pola keyakinan dalam keberagamaan ini semakin hari semakin membias dan membuka peluang untuk ditafsir dengan sebebas-bebasnya versi kaum laki-laki. Hal inilah yang memberikan peluang bagi kaum laki-laki melakukan tindakan kekerasan, pelecehan dan seterusnya.

Selain itu, ada anggapan yang melekat dalam diri kaum laki-laki, bahwasanya perempuan adalah barang milik. Sebagai barang milik, laki-laki berhak untuk melakukan apa saja terhadap perempuan tersebut. Secara umun disepakati bahwa setiap orang tentu mempunyai hak mutlak untuk memanfaatkan barang dimilikinya. Pemilik punya wewenang untuk mendayagunakan apa saja yang dimiliki termasuk perempuan. ${ }^{69}$ Kaum perempuan statusnya seperti barang yang bisa dimanfaatkan atau difungsikan sesuai keinginan pemiliknya. Mereka dianggap sebagai barang milik yang memungkinkan pemiliknya berbuat apapun sesukanya tanpa perlu memperhatikan aspek psikologis perempuan tersebut. Disinilah problem terbesar muncul yaitu terabaikan isi perasaan dan rasa kaum perempuan.

Anggapan ini tidak sepenuhnya salah, tetapi ada hal yang penting yang diabaikan atau mungkin dilupakan. Laki-laki tidak menyadari bahwa sebagai makhluk Allah mempunyai

${ }^{69}$ Budhy Munawar. Rachman. Islam Pluralis: Wacana Kesetaraan Kaum Beriman. (Jakarta: Penerbit Paramadina, 2001), h. 394. 


\section{An-Nisa', Volume XI Nomor 1 Januari 2018}

kewajiban dan tanggungjawab dalam memanfaatkan sumber daya alam dan manusia di permukaan bumi. Setiap sikap dan perilaku serta kebijakan yang diambil oleh manusia dihadapkan dengan etika, norma dan undang-undang yang berlaku dari Allah. Sudah tegas dikatakan bahwa setiap manusia adalah dituntut untuk mempertanggungjawabkan segala akivitasnya di permukaan bumi.

Dengan demikian, ketika aktivitas manusia dibatasi regulasi yang mengikat sejatinya manusia tidak berhak untuk mengklain dirinya memiliki sesuatu. Kepemilikan mutlak hanya Allah saja. Dalam hal ini, laki-laki tidak boleh mengaku baik dari sikap dan tindakan sebagai pemilik perempuan yang dapat mendayagunakan semau dirinya. Hubungan laki-laki dan perempuan adalah hubungan sinergitas yang simbiosis mutualistik. Keduanya membentuk struktur dan fungsi untuk menjalankan sistem kekhalifahan hamba Allah di permukaan bumi. Dalam struktur dan fungsi yang terjadi adalah pemetaan hak dan kewajiban di antara anggota. Komunikasi wanita dan pria dibangun atas saling membutuhkan dan saling berbagi untuk menyempurnakan tugas masing-masing sebagai hamba dan khalifah. Salah satu dari mereka tidak ada yang lebih tinggi, seandainya jika terdapat pembagian tugas dan struktur itu hanya untuk terselenggaranya sistem tata kehidupan dengan baik yang diorientasikan pada visi penghambaan.

Struktur dan fungsi ini memang dipopulerkan oleh ilmuwan sosiologi barat tetapi sejatinya topik ini telah disinggung oleh Nabi Muhammad Saw dulu. Beliau telah menegaskan bahwa setiap individu di permukaan bumi mempunyai tanggung jawab yang mengikat. Tanggung jawab dalam paradigma modern dapat diterjemahkan sebagai struktur sosial yang membentuk fungsi dan tanggung jawab. Untuk fungsi dan tanggung jawab tersebut, terdapat aturan yang mengikat sebagai pertanggungjwaban (akuntabilitas) dalam aspek sosial dan dimensi agama. Untuk itu, aspek teososiosentris dalam hubungannya manusia sebagai makluk sosial dan makhluk beragama harus benar-benar diperhatikan. ${ }^{70}$ Laki-laki dan perempuan memiliki kedudukan masing-masing secara alami dan berdasarkan kodratnya. ini adalah given tidak bisa direkayasa oleh manusia

${ }^{70}$ Lihat hadits yang diriwayatkan Imam Buhkari dari Abdullah ibn Umar. Haasyiah 'alaa Mukhtashar Abii Hamzah li Al-Bukhari (Surabaya:Nuruh Hidayah), h. 69. 
seperti perempuan melahirkan sedang laki-laki bertanggung jawab untuk menyuplai kebutuhan rumah tangga. Hubungan kedua belah pihak adalah sifatnya patnership yang membagi tugas sesuai dengan kapasitasnya bukan hubungan instruktif.

\section{Kesimpulan}

Tafsir keberagamaan dalam memposisikan perempuan sangat dipengaruhi oleh internalisasi subyek ke dalam obyek sehingga terlihat adanya pola subjective cum objective dan objective cum subjective. Tafsir yang dikembangkan selama ini tentang kedudukan perempuan sangat berbau arogansi kaum laki-laki yang selama ini menjadi pemegang otoritas penafsiran. Kedepannya harus ada upaya dini untuk memposisikan perempuan sesuai kodrat yang sebenarnya dengan merekonstruksi keagamaan dengan memperhatikan nilai human equality dan keadilan untuk semua golongan.

Ajaran Islam yang sebenarnya memposisikan manusia sebagai pemimpin (khalifah) yang bertugas untuk mengabdi kepada Allah di muka bumi. Manusia sebagai komunitas senantiasa membentuk sturuktur dan fungsi sehingga melahirkan hak dan kewajiban. Hal ini yang perlu untuk diluruskan dan dikembalikan kepada posisi yang sebenarnya untuk menjunjung nilai ketakwaan sebagai basis utama yang menentukan kemuliaan seseorang di hadapan Allah SWT.

\section{Daftar Pustaka}

Abdullah, M.Amin. Agama, Ilmu dan Budaya; Paradigma Integrasi-Interkoneksi Ilmu Pengetahuan. Yogyakarta, Makalah disampaikan dalam pidato AIPI 17 Agustus, 2013. Al-sy-Syanusi, Muhamad Ibn Ali Asy-Syafi’ie. Haasyiah ‘alaa Mukhtashar Abii Hamzah li AlBukhari. Surabaya: Nurul Hidayah

Arivia, Gadis. Filsafat Berperspektif Feminis. Jakrta: Yayasan Jurnal Perempuan, 2003.

Departemen Agama. Al-Qur'an dan Terjemahannya. Semarang: CV. Asy-Syifa, 1999.

Faqih, Mansoer. Membincang Fenimisme; Diskurusus Gender Perspektif Islam. Surabaya: Risalah Gusti, 2000.

Marzuki. Tt. Kekerasan gender dalam wacana tafsir keagamaan di Indonesia dalam perspektif islam. Yogyakarta: FISE-UNY 


\section{An-Nisa', Volume XI Nomor 1 Januari 2018}

Nawawi, Muhamad. Tahun terbit. Maaraah Labiid Tafsiir An-Nawawi. Surabaya: Alhidayah

Rachman, Budhy Munawar 2001. Islam Pluralis: Wacana Kesetaraan Kaum Beriman. Jakarta:

Paramadina, 2001. 